\title{
LA FORMACIÓN DEMOCRÁTICA DE LOS NIÑOS Y JÓVENES
}

\author{
Diego Antonio Pineda R.(1)
}

Resumen: Se examina aquí tanto la idea general de democracia, sustentada en tres metacriterios fundamentales (bien común, justicia y libertad individual) como el tipo de formación democrática que requieren hoy los niños y jóvenes. Para ello, se propone una concepción del "animal político" aristotélico (que incluye a niños y jóvenes) dentro de la cual éstos son a la vez el fermento necesario de la vida democrática y un potencial peligro para ella. Se opta finalmente por proponer una comunidad de indagación como el ambiente privilegiado para la formación democrática.

La democracia es un modo de vida personal que no está guiado por la mera creencia en la naturaleza humana en general, sino por la fe en la capacidad de los seres humanos para juzgar y actuar inteligentemente en las condiciones apropiadas. (...). Las garantías puramente legales de las libertades civiles, la libertad de credo, expresión y reunión son un pobre aval si en la vida cotidiana la libertad de comunicación, el intercambio de ideas, hechos y experiencias se anula con la sospecha mutua, los ultrajes, el miedo y el odio. Todo ello quiebra las condiciones básicas del modo de vida democrático con mayor efectividad incluso que la coerción abierta, la cual es operativa cuando logra alimentar el odio, la sospecha y la intolerancia en el espíritu de los seres humanos

\section{John Dewey}

Puesto que una sociedad democrática es aquella en la que ninguna cuestión social puede quedar libre de investigación, no es posible suponer que haya un conjunto de creencias que deba ser considerado como 'intocable' por parte de los niños y jóvenes que se están preparando para participar en este tipo de sociedad de una manera activa y responsable. El problema no consiste tanto en conseguir que los niños y jóvenes que se están formando como ciudadanos sepan esto o aquello, $o$ crean en esto o aquello (...). No, el problema consiste simplemente en que el primer criterio que permite distinguir a un ciudadano responsable es -y siempre ha sido- la capacidad de pensar de un modo crítico y reflexivo. Un sistema educativo que no estimula a los niños y jóvenes a reflexionar, a pensar de forma sistemática y cuidadosa en los asuntos que les importan no consigue prepararlos para cumplir el único criterio que debe ser satisfecho si uno no quiere ser simplemente un miembro más de una sociedad, sino un buen ciudadano en una democracia.

\section{Matthew Lipman}

Hay palabras que, a fuerza de usarlas por todos y para todo, se hacen triviales y llegan a desgastarse hasta perder su significado originario. "Democracia" es una de 
aquellas palabras. Todos hablamos de democracia: los políticos, los gobernantes, el ciudadano común... y también nosotros mismos, los maestros, y hasta los propios niños y jóvenes. En nombre de la "democracia occidental" se justifican guerras absurdas en donde las superpotencias del mundo despliegan todo su poderío militar contra pueblos indefensos o los someten, mediante bloqueo económico, al hambre y la destrucción. "Defender las instituciones democráticas" ha llegado a convertirse en una de aquellas frases de cajón que los poderosos y los políticos corruptos enarbolan con el fin de defender en más de una ocasión sus oscuros y mezquinos intereses particulares. "Democráticas" se han llamado a sí mismas repúblicas en donde la represión policial y la restricción de las libertades individuales han llegado al extremo y en donde la justicia y la libertad han brillado por su ausencia. Para colmo, las democracias que conocemos no son muchas veces más que estructuras políticas que, aunque formalmente defiendan ciertos principios y cuenten con cierto tipo de instituciones (un Parlamento, una Constitución escrita, un sistema electoral, el reconocimiento de una serie de derechos inalienables de los individuos, unos mecanismos de participación ciudadana), en su actuar concreto nos siguen pareciendo sociedades jerárquicas, cerradas y resistentes al cambio que se encargan ellas mismas de proclamar como uno de sus principales propósitos.

"Democracia" es, pues, un término ambivalente cuya sola pronunciación suscita emociones encontradas. Para unos se trata de un nombre sacrosanto cuya mera enunciación debe implicar asentimiento. Para otros de una meta histórica lograda a la que bastará hacerle unos ajustes que permitan "consolidarla". Para unos terceros de un error histórico, o de un engaño de la burguesía, que hay que suprimir cuanto antes con la fuerza de las armas. Para otros, en fin, entre quienes me cuento, de un ideal nunca realizado plenamente, el cual, y a pesar de sus muchas inconsistencias, constituye la única forma de gobernar nuestras vidas que se adapta a nuestra imperfección y finitud.

Podría alguien preguntarnos, dado lo que hemos dicho hasta aquí, qué sentido puede tener entonces que nos ocupemos hoy nuevamente de la democracia, que gastemos más palabras intentado dar significado a una palabra que parece haber perdido todo significado. ¿Para qué hablar más de democracia? ¿No caemos con ello, tal vez, en el discurso electorero del político de turno? Más aún. ¿Qué sentido puede tener lo que aquí nos proponemos: reflexionar en torno a la formación de ciudadanos para una sociedad democrática? ¿Por qué ocuparnos de la formación en y para la democracia de niños y jóvenes? Todavía más: ¿qué sentido puede tener esto en los países del tercer mundo, sumidos en el caos y la violencia?

Es sin duda imposible ofrecer una respuesta que pudiera ser medianamente convincente a interrogantes tan fundamentales como estos. Permítanme, sin embargo, que exprese una convicción que creo que considero fundamental: a pesar de lo difícil, y hasta de lo contradictorio, que resulta hablar de "democracia" en países sumidos en la desconfianza y atemorizados por el terrorismo de izquierda y derecha, sometidos a la desesperanza por un Estado débil e incapaz de responder con eficacia a las demandas sociales, y con un tejido social gravemente deteriorado por la corrupción, el narcotráfico, el desempleo y la pobreza; a pesar de todo ello, 
necesitamos hoy más que nunca más (y no menos) democracia. Es decir, precisamos, por la propia encrucijada histórica en que nos encontramos, de espacios para la discusión abierta, para las propuestas reflexivas, para la escucha de las perspectivas del otro y para el diálogo que ponga freno a nuestra irracional violencia. Es ampliando los espacios democráticos, y no metiéndonos en la aventura de una guerra loca que nunca sabemos a donde conduce ni cuando termina, que podemos enfrentar las dificultades que nos aquejan.

No quiero con lo anterior, sin embargo, idealizar la democracia. La democracia no es ciertamente ni el único ni necesariamente el mejor modo de organizar nuestra propia existencia personal y social. No es, ni mucho menos, una forma de gobierno ideal. Por cierto, experimentamos con frecuencia en nuestras vidas muchos de sus fracasos e imperfecciones. Con todo, preguntaría, como lo hiciera Churchill en alguna ocasión, quién ha encontrado una forma mejor. En su propia limitación radica, sin embargo, la fuerza de la democracia. Su virtud está en su propia imperfección, en su carácter siempre frágil, en la radical modestia que impone a quien detenta la autoridad y, sobre todo, en su propio sentido de la no-verdad, es decir, en el hecho de que en una auténtica democracia no puede apelarse en ningún momento a verdades últimas (ni siquiera a la propia democracia como verdad última), sino que siempre es necesario ensayar el camino de la indagación, del diálogo, de la experimentación de nuevas posibilidades, de la escucha y exploración de puntos de vista alternativos.

No se trata, pues, de que entremos ahora en la discusión general en torno al sentido de la democracia. Aceptemos a ésta como un ideal histórico vigente y preguntémonos más bien por cuál es el tipo de democracia que deseamos y por qué puede tener sentido el que lo deseemos. Sólo sobre la base de lo que encontremos en ello podremos abordar con mayor claridad el problema de la formación democrática de los niños y jóvenes.

\section{1. ¿Por qué y cuál democracia?}

Permítanme que me remita para enfrentar la anterior pregunta a una pequeña anécdota que siempre he encontrado aleccionadora. Ian, un niño de seis años de edad que se disgusta al ver que tres niños, hijos de los amigos de sus papás, se toman el televisor y le impiden ver su programa favorito, pregunta a su mamá con cierto grado de frustración: "Mamá, ¿̇por qué es mejor el egoísmo de tres personas que el de una?" (Matthews, 1986, p. 45).

Este pequeño suceso, y sobre todo la ingenua pero demoledora pregunta de lan, creo que nos ayudan a plantear un asunto fundamental. Es claro que lan no está preguntando, por ejemplo, por qué es más conveniente satisfacer a tres personas que a una, ni por qué es asunto de buena educación complacer al visitante. Lo que él está preguntando es algo más radical: "¿por qué es mejor?", es decir, por qué es de mayor calidad moral lo que desean tres personas que lo que sólo desea una persona. Al fin y al cabo, considera Ian, se trata de dos cosas que tienen la misma calidad moral. Se trata de dos formas de egoísmo que sólo difieren en un aspecto: en su número (un egoísmo lo comparten tres personas, el otro es el egoísmo de 
una sola persona). Lo que pone en cuestión, pues, la pregunta de este niño es el criterio de la mayoría como criterio de calidad moral. Lo que para él resulta extraño es que necesariamente sea mejor lo que desea un mayor número de personas que lo que desea una sola persona. Si ambos, el conjunto de tres y la persona sola, desean lo mismo, esto es, satisfacer su egoísmo, no hay ninguna razón para pensar que sea mejor lo que hacen unos que lo que hace el otro. El criterio de la mayoría, pues, no parece ser un fundamento suficiente para decidir sobre la bondad de una determinada decisión.

Puesto que la democracia como forma de gobierno y de vida se justifica a sí misma en muchas ocasiones por el criterio de la mayoría, cabe preguntar ahora, parafraseando la pregunta de lan, ¿̇por qué es mejor la democracia (una forma de gobierno basada en el deseo y la opinión de muchos) que, por ejemplo, la monarquía (una forma de gobierno que se funda en el deseo y la opinión de una persona)? Como vemos, semejante pregunta no admite una respuesta absoluta. No hay nada que nos permita afirmar con certeza que es mejor el egoísmo de tres personas que el de una, como tampoco hay nada que nos permita decir que necesariamente es mejor la democracia que la monarquía. De hecho, por ejemplo, en algunos países europeos como España, ha sido la monarquía la que ha garantizado la consolidación de la democracia.

No hay nada, pues, que nos pueda decir que, en sentido absoluto, es mejor la democracia que otra forma de gobierno. A lo mejor, para usar una bella fórmula del gran Aristóteles, la democracia no sea más que "la mejor forma de gobierno posible según las circunstancias". Es decir, no la mejor en sí misma, sino sólo dada la condición propia de los hombres que somos hoy y aquí. Tal vez se trate únicamente de lo que hemos sugerido previamente: la democracia es aquella forma de gobierno imperfecta que mejor se acomoda a nuestras propias imperfecciones. Si ello es así, no podemos decir por qué es mejor, sino que sólo podemos intentar saber por qué y bajo qué condiciones preferimos nosotros la democracia.

Preguntémonos, entonces, lo siguiente: ¿por qué razón preferimos la democracia a otra forma de gobierno? Subrayo el término "razón" para indicar que lo que busco es algún tipo de argumento que nos pueda mostrar por qué es más razonable vivir democráticamente que, por ejemplo, bajo un régimen autoritario, y no simplemente la causa por la cual nosotros de hecho preferimos la democracia, pues es muy probable que la causa de nuestro apego a la democracia no sea otra que la incapacidad para imaginarnos algo distinto a ella o la mera costumbre de vivir bajo un régimen que se identifica con dicho nombre.

Pero volvamos sobre nuestra pregunta: ¿jpor qué razón hemos de preferir la democracia? No hay tampoco aquí razones absolutas. Alguien podría decir, por ejemplo, que sería mejor entregar la responsabilidad sobre el gobierno de nuestras vidas (es decir, la administración de nuestro hogar, de nuestras escuelas, de nuestras ciudades, de nuestro país y hasta de nuestra propia vida personal) a una élite intelectual, a unos cuantos "ilustrados", quienes podrían, seguramente mejor que nosotros mismos, decidir sobre lo que nos conviene y sobre lo que es bueno y 
justo para todos. Esta posibilidad, sin embargo, nos aterra, pues -aún si fuera cierta- nos despojaría de la propia responsabilidad de nuestra vida y nos haría seres por completo heterónomos e incapaces de decidir con criterio sobre nuestro propio ser.

El atrevernos a pensar en semejante hipótesis nos revela, sin embargo, algo esencial en torno a la noción de democracia. Aquello a lo que no quisiéramos -y aún si quisiéramos no podríamos- renunciar por ninguna razón y bajo ninguna circunstancia es precisamente a ser lo que somos y a decidir por nuestra propia cuenta sobre lo que sentimos, deseamos y pensamos. Ello resulta imposible bajo un régimen dictatorial, así se trate de la hipotética dictadura "ilustrada" que previamente nos imaginábamos. Y ello es precisamente lo que, de una forma $\mathrm{u}$ otra, permite y garantiza un régimen democrático. Si preferimos la democracia es precisamente porque preferimos la libertad a la esclavitud, el pensar por nosotros mismos a las verdades de los "ilustrados", el riesgo de asumir nuestras vidas a la fácil rutina de hacer lo que otros nos mandan. Este, creo yo, es el fundamento último y único de toda democracia: un modo de gobierno en donde cada uno puede ser lo que él mismo ha elegido para sí y en donde ha tenido ocasión de hacer esa elección de una forma libre y razonada.

Preferimos, pues, la democracia. Esto parece claro. Pero, ¿̇cuál democracia? ¿Qué requisitos debe cumplir una cierta forma de vida personal y política para que podamos considerarla con certeza una "democracia"? Empecemos por algo que no por evidente deja de ser cierto: aspiramos a una democracia real. Es decir, aspiramos no sólo a un régimen de vida en donde nos quedemos en la declaración formal de bellos principios, sino a poder vivir según principios que son producto de nuestra elección y que de algún modo satisfacen nuestras necesidades más sentidas en tanto seres humanos.

Estaría de sobra decir lo anterior si no viviéramos precisamente en un país y en un mundo en donde muchas veces la democracia no es más que un asunto de forma. No sólo el término "democracia formal" se usa con frecuencia en la teoría política, sino que, de hecho, son muchas las dictaduras que se han instaurado, en Latinoamérica y en otras partes del mundo, bajo una fachada democrática.

Veámoslo en una situación concreta. ¿Podríamos afirmar con certeza que tenemos una democracia más viva, más madura o más auténtica por el hecho de que una Constitución Política nos defina como "un Estado social de derecho" o porque esa misma constitución haya instaurado interesantes mecanismos de participación ciudadana o de defensa de los derechos individuales como la acción de tutela, la acción popular, la iniciativa legislativa o el cabildo abierto? Sin negar el inmenso valor de tales mecanismos, y aún creyendo firmemente en que de esa forma se abren caminos insospechados para el desarrollo de una sociedad democrática, haríamos mal, sin embargo, si nos contentáramos con ello. Ellos no son nada sin ciudadanos conscientes y razonables que ejerzan su función como tales ciudadanos. No son nada sin una sociedad civil organizada y firme que sea capaz de enfrentar los factores de violencia y desestabilización. No son nada sin un Estado fuerte que sea capaz de hacer cumplir lo pactado. No son nada sin un 
sistema de justicia que genere confianza con sus procedimientos y decisiones. No son nada sin un grupo de líderes comunitarios y sociales capaces de expresar los intereses colectivos sin caer en el fácil juego de los privilegios que otorga el poder.

Por desgracia, nos hemos acostumbrado a identificar la democracia con el mero cumplimiento de una serie de requisitos formales, como la existencia de una Constitución escrita, un Parlamento, un sistema electoral, o el reconocimiento de ciertos derechos a las minorías. Todos conocemos, sin embargo, países en donde la Constitución escrita proclama a un antiguo dictador como senador vitalicio o como jefe supremo de las Fuerzas Armadas. Conocemos también países en donde el Parlamento no ejerce control político alguno porque está formado por los propios miembros del Partido que detenta el poder ejecutivo, o porque, aún perteneciendo a la oposición, su oposición no es más que de nombre y sólo sirve como contrapartida en el reparto burocrático; o donde, simplemente, el Parlamento no es más que un instrumento decorativo, pues sus decisiones pueden ser borradas de un plumazo por un Presidente o Primer Ministro con poder de veto. Sabemos también de lugares en donde el sistema electoral no cumple otra función que la de repartir cada cuatro años el poder entre miembros de un mismo partido y de países en donde los derechos de las minorías, aunque se reconozcan de palabra, se violan de modo flagrante.

En el episodio 2 del Capítulo I de Marcos, una novela de filosofía política, escrita por Matthew Lipman y perteneciente al programa "Filosofía para Niños"(2), se aborda el problema que acabamos de mencionar. Marcos discute allí con sus compañeros en qué consiste una democracia y se pregunta cuáles son los criterios a partir de los cuales podemos juzgar si un determinado país merece el título de democrático. Los criterios que se tocan allí son los mismos que hemos mencionado previamente: una Constitución, un sistema electoral, un Parlamento, unos derechos reconocidos a las minorías, etc. Lo que Marcos empieza a descubrir a medida que se sucede la discusión es que tales criterios, siendo válidos en sí mismos, no son por sí solos indicadores de la existencia de una democracia, y que ni siquiera tomados todos ellos en conjunto garantizan la existencia de una democracia real y efectiva.

Ahora bien. Si la democracia no se identifica con la presencia de ninguna institución en particular ni está garantizada por ningún mecanismo específico de participación o de defensa de los derechos individuales, ¿qué es, entonces, lo que hace que haya una democracia?

Para responder a esta pregunta, que creo la fundamental, permítanme que retome aquí la terminología elaborada por Matthew Lipman y su distinción entre criterios y metacriterios(3). Si un criterio es "una herramienta para juzgar", que nos permite elegir razonadamente entre distintas opciones, un metacriterio nos permite elegir a su vez entre diversos tipos de criterios aquellos que son más relevantes para la clarificación de una situación, la elaboración de un juicio o la toma de una decisión. Si aplicamos esta distinción al asunto de la democracia, podemos comprender que para juzgar algo como democrático utilizamos un cierto conjunto de criterios básicos. Entre tales criterios conviene destacar los siguientes: 
- la existencia de unos principios generales de acción legítima y de unas reglas de juego que son objeto de conocimiento público (lo que en un país estará garantizado por la Constitución escrita);

- la posibilidad de que todos aquellos que se vean afectados por un determinado asunto tengan ocasión de participar en las decisiones que los comprometen (lo que en un régimen político implica la creación de mecanismos efectivos de participación ciudadana);

- la consagración de ciertos mecanismos a través de los cuales se puedan hacer valer los derechos reconocidos a los individuos y se hagan cumplir los compromisos públicamente adquiridos (lo que en un régimen democrático se traduce en mecanismos de defensa de los derechos individuales y de solución de las necesidades públicas).

- la existencia de medios a través de los cuales los individuos puedan manifestar su inconformidad y puedan ejercer el derecho a disentir (lo que en una democracia política conduce a la creación de mecanismos para el ejercicio de la oposición y la protesta legítimas).

Aunque no pretendo afirmar que éstos sean los únicos criterios que determinan un carácter democrático, considero sí que son ellos por lo menos los requisitos formales mínimos para que en algún sentido pueda hablarse de democracia. Utilizando la terminología de Kant, diría que ellos constituyen la "condición de posibilidad" del juego democrático, es decir, que sin que estos requisitos mínimos se cumplan es impensable incluso la idea de democracia.

Ahora bien. Lo que es requisito indispensable no es por ello mismo garantía necesaria. Es decir, del hecho de que se cumplan ciertas condiciones de posibilidad no se sigue de un modo necesario la existencia de un régimen democrático. Tales criterios no son absolutos y necesitan ellos mismos ser evaluados. Pero, puesto que los criterios son evaluables también a la luz de otros criterios, es preciso pensar en cuáles pueden ser dichos metacriterios a la luz de los cuales podemos dar cuenta de los criterios enunciados. Aunque esos metacriterios podrían ser muchos más, considero que hay tres que son en principio indispensables: el bien común, la justicia y la libertad individual. Me ocuparé a continuación brevemente de cada uno de estos tres metacriterios de la democracia.

\section{El bien común}

Es cosa frecuente que, en una organización democrática cualquiera, entren en conflicto intereses y derechos individuales. Es muy probable que se trate de intereses y derechos que sean legítimos, bien sea de un ciudadano o de una porción de ciudadanos. Supongamos, por ejemplo, que es preciso construir una carretera que atraviese por el predio de una persona y que, no habiendo otra posibilidad, sea necesario derribar la casa de dicha persona. Sin duda, ella puede reclamar legítimamente su derecho a residir allí. Sin embargo, hay un interés más elevado que su propio derecho individual, pues si él no permite que pase por allí la 
vía se verán perjudicados miles, y hasta millones, de ciudadanos. Parece evidente, entonces, que deban primar los intereses de un número mayor de personas afectadas que los de una sola persona, pues lo que entra en conflicto es el interés individual con el interés común. Sin duda, vivir en su casa es para esta persona un bien, y merecerá una indemnización justa que repare el daño que se le causa; pero, ante la imposibilidad de que dos bienes tengan lugar al mismo tiempo, debe primar el fundamental de ellos, que es el bien común.

Algo semejante puede ocurrir en los hogares o las escuelas cuando se trata de defender o reclamar derechos. Los niños de hoy, que ya tienen una elevada conciencia de sus derechos, suelen con frecuencia reclamar a sus padres o maestros por el incumplimiento de algunos de sus derechos. Aunque es muy fundamental en su educación en y para la democracia que los niños conozcan y exijan sus derechos, es fundamental también que aprendan a evaluar cuándo la defensa a ultranza de sus derechos va en perjuicio del bien común. Los derechos no son absolutos, tienen un límite, que está marcado por los derechos de otros y, sobre todo, por el bien común. El bien común es, pues, el primero de los metacriterios básicos a la luz de los cuales pueden ser evaluados los conflictos de intereses, de derechos o de criterios en el marco de una democracia. Es, por ello, uno de los referentes básicos del Derecho, en cuanto éste pretende servir al cuidado del bien común.

\section{La justicia}

Como bien lo ha señalado John (1998), la justicia es el criterio último a la luz del cual se juzgan todos nuestros asuntos prácticos. Por ello mismo, resulta impensable cualquier régimen que no responda a la exigencia de justicia. Esto es particularmente cierto de la democracia, que tiene su origen precisamente en la pretensión de los antiguos griegos de organizar un régimen de vida en el cual se realizara en la polis el ideal supremo de la justicia. Ello es cierto a tal punto que, incluso el más grande crítico de la democracia griega, Platón, lo hace a la luz de una idea de justicia que no logra él ver realizada en una sociedad en donde Sócrates, considerado por él el hombre bueno y justo por excelencia, se vio sometido a los vaivenes de las decisiones políticas de un grupo que actuaba en defensa de sus intereses particulares.

Es tan fundamental la justicia como metacriterio de la democracia que cualquier otro criterio de los señalados puede y debe ser evaluado a la luz de este metacriterio. Es cierto que, en una democracia, debe haber participación. Pero allí no acaba el asunto, pues ¿cómo sabemos que se trata de una participación justa? Es cierto que la ley debe ser respetada en una democracia; pero, cqué ocurre cuando se trata de una ley que es abiertamente injusta?, ¿qué debe primar: la justicia o el derecho? No basta con reivindicar derechos, pues será preciso siempre justificarlos, es decir, mostrar que son justos. ¿Es justo un derecho? ¿Es justa una determinada decisión? ¿Es justa la Constitución de un país? ¿Es justa una ley? Son éstas preguntas que siempre será legítimo hacer en una democracia, pues no hay auténtica y plena democracia sino en la medida en que se viva dentro de un orden justo. La justicia es la exigencia suprema de la democracia. La democracia no sólo 
es impensable sin la idea de justicia, sino que también es ella el metacriterio a la luz del cual se han de juzgar los acuerdos entre ciudadanos, las relaciones de éstos entre sí y con el Estado y los propios mecanismos de participación ciudadana y de defensa de los derechos individuales.

\section{La libertad individual}

Que el fin de todo régimen político y de toda forma de organización humana es el más elevado desarrollo de los individuos, esto es, el más pleno despliegue de sus diversas potencialidades es una de las grandes ideas desarrolladas por la filosofía política del siglo XIX, especialmente por autores como Guillermo de Humboldt y John Stuart Mill(4). Siendo la justicia el bien más preciado desde el punto de vista de la sociedad en su conjunto, es, sin embargo, la libertad aquel bien que permite a los individuos el máximo disfrute de todos los bienes. Y es que la democracia es precisamente un modo de vida en donde el individuo dispone de las condiciones para el ejercicio de su libertad de una forma creativa, o, para decirlo en palabras que nos resultan más cercanas, para "el libre desarrollo de su personalidad".

En una auténtica democracia todo apunta a garantizar las libertades del individuo y a permitir que, por el uso de su propia razón, pueda realizar libremente lo que libremente ha elegido siempre y cuando ello no interfiera con la libertad de otros. "iSapere aude! Sírvete de tu propio entendimiento" fue el lema que, retomado por Kant(5), ha servido desde siempre como inspiración de todo ideal democrático auténtico. Esta libertad individual se expresa de forma especial a través del derecho que cada individuo tiene, no sólo de pensar por sí mismo, sino incluso de disentir de otros, siempre y cuando este disentimiento no se exprese bajo formas violentas que nieguen los derechos de los demás.

Contra la tendencia cada vez más marcada a definir la democracia como espacio en donde se generan consensos, y sin desconocer lo que de válido pueda haber en dicha idea, creo que lo que distingue esencialmente a un ámbito democrático de otro que no lo es es precisamente la posibilidad que existe en dicho ámbito de disentir, de no comulgar necesariamente con la opinión de la mayoría. Una auténtica democracia es precisamente el lugar en donde cada uno de los individuos mantiene una lucha personal con otros, y especialmente consigo mismo, para formarse una opinión a la vez propia, ilustrada y mediada por la interacción con las opiniones y puntos de vista de otros. Como bien ha señalado Estanislao Zuleta (1995, p. 75), "una cultura democrática no es una cultura de mayorías. (...). Llamamos democracia al derecho del individuo a diferir contra la mayoría; a diferir, a pensar y a vivir distinto; en síntesis, al derecho a la diferencia. Democracia es derecho a ser distinto, a desarrollar esa diferencia, a pelear por esa diferencia, contra la idea de que la mayoría, porque simplemente ganó, puede acallar a la minoría o al diferente".

Tales metacriterios de la democracia, aquí apenas esbozados, requieren de un tratamiento más detenido y de un desarrollo teórico y práctico mayor. No debemos engañarnos, sin embargo. No constituyen ellos asunto de cuantificación ni pueden ser aplicados sin más. Tales metacriterios no se cumplen ciertamente de un modo 
absoluto en ninguna parte. Tienen, a pesar de todo, el valor de ser ciertas "ideas regulativas" que marcan el camino que nos conduce hacia una auténtica democracia.

Ello no quiere decir tampoco que sean elementos de juicio de un carácter puramente abstracto. No, los metacriterios de la democracia también son y pueden ser concretos. Ello depende en gran medida del modo como los asumamos. Bien común, justicia y libertad son los criterios a la luz de los cuales podemos evaluar nuestros propios criterios para juzgar el carácter democrático de una situación, de una persona o de una institución como nuestra familia, nuestro colegio o nuestra sociedad. Poner a funcionar en la práctica estos criterios y metacriterios es precisamente la tarea más importante de todo esfuerzo de formación democrática. También los niños y los jóvenes son sensibles a estos criterios y metacriterios y también ellos, en tanto seres políticos, están en condiciones de juzgar las situaciones en que están comprometidos a la luz de criterios ético-políticos relevantes. Es así como de esta tarea de construcción de una comunidad democrática no queda excluido nadie, no sólo porque todos tenemos derecho a participar en ella por nuestra simple condición de hombres, sino porque también, como los adultos, los niños y jóvenes comparten también nuestra condición de "animales políticos".

\section{El niño y el joven como "animales políticos"}

Cuando, en el primer libro de La Política, Aristóteles define al hombre como un "animal político", es claro que lo que tiene en mente es un personaje muy específico: el varón adulto ciudadano libre de una ciudad griega como Atenas, con exclusión del bárbaro, del esclavo, de la mujer y, por supuesto, de los niños y de los jóvenes, que no han alcanzado la mayoría de edad por la cual se les conceden derechos políticos. Con el tiempo una definición tan restrictiva del "animal político" ha venido ampliándose. Ya desde los tiempos de la antigua Roma y del cristianismo paulino, que negaba la diferencia entre esclavo y libre, entre bárbaro y griego, o entre judío y gentil, y pasando por los muchos desarrollos de la modernidad que han venido a suprimir formas terribles de esclavismo, hemos visto ya en nuestros tiempos el tremendo impulso que a la dinámica social le imprime la presencia cada vez más activa de la mujer en las tareas sociales. Sólo nos queda hoy por reconocerle su condición de ser político a los niños y jóvenes.

Si la política no ha de confundirse con el mero ejercicio de la participación en las decisiones colectivas mediante la elección de nuestros representantes, sino que ha de entenderse como la participación efectiva en las tareas que atañen a todos, no se ve razón por la cual pueda decirse que el niño o el joven no ejerzan una función política. Su vocación política se manifiesta ya desde sus primeros intentos de cooperación en las actividades que realizan con sus pares (por ejemplo en sus juegos simbólicos y de reglas) y en su creciente interés por colaborar en la realización de las tareas propias de los adultos. De otra parte, y en un hecho que no por reprobable deja de ser cierto, los niños de hoy, ya desde muy temprana edad, adquieren un lugar en las luchas políticas: una buena parte de ellos es empleado en las guerras en labores de espionaje, sabotaje y asalto; otra es utilizada 
en las luchas sociales como rehenes o escudos humanos; otros más son instrumentalizados políticamente para servir a fines unas veces loables y otras veces no tanto. Estamos ya retrasados en reconocer el lugar que en la política actual desempeñan niños y jóvenes.

La participación política de los niños es hoy un hecho. No deja de ser, sin embargo, un hecho que entraña muchos peligros. Y ello por varias razones. En primer lugar porque su perspectiva de mundo, con todo y lo razonable que pueda ser, es aún muy limitada. Lo que tienen de intuitivos suele faltarles en experiencia de la vida, lo que es precisamente esencial para desarrollar una acción política fructífera y razonable. En segundo término porque, dada su condición de heteronomía y de dependencia respecto del adulto, son fácilmente manipulables por éstos y, en más de una ocasión, representan una amenaza potencial para el propio ejercicio democrático. Una prueba de ello puede verse en la utilización que se hace de los niños con fines militares: desde el punto de vista de la estrategia los niños son excelentes soldados, perfectos para el espionaje, el atentado y la acción cruel y despiadada. Todo esto porque, pudiendo ser el niño un ser racional y razonable, con frecuencia no es su capacidad racional lo que se cultiva, sino sus instintos de muerte o su disposición gregaria o servil.

Y es que los niños no suelen ser democráticos. Al contrario, muchos de ellos tienden a sojuzgar, a discriminar y a destruir a otros. Ello en buena medida resulta necesario, pues es fruto de su afán de autoafirmación y de su necesidad de construir una identidad. Ahora bien. Que los niños no suelan ser democráticos no implica de ningún modo que no puedan llegar a serlo. Los niños pueden desarrollar sentimientos, actitudes y puntos de vista democráticos siempre y cuando se les forme para ello. Más aún, el desarrollo intelectual, afectivo, social y moral de los niños los conduce precisamente hacia la formación de una conciencia democrática.

En sus estudios sobre el desarrollo de la conciencia moral en el niño y de su sentido de la justicia, Piaget y Kohlberg nos han mostrado de modo fehaciente de qué manera se van desarrollando paulatinamente en los niños y jóvenes patrones de acción de carácter democrático. Ello puede observarse, por ejemplo, en la evolución de sus juegos, que pasan de ser en los primeros estadios del desarrollo actividades aisladas de desarrollo motriz hasta llegar a convertirse en niveles más avanzados (a partir aproximadamente de los ocho años, cuando empiezan a tomar forma los juegos de reglas) en actividades de socialización y, sobre todo, de negociación de las reglas a la luz de la consideración de las necesidades del juego mismo y de los intereses de sus participantes. También la noción de justicia, analizada ampliamente por Kohlberg, presenta rasgos semejantes, pues su evolución puede rastrearse a lo largo de tres niveles y seis estadios en donde la orientación individualista del castigo y la obediencia llega a transformarse en una noción social de justicia fundada en la idea de pacto e incluso en la búsqueda de acciones guiadas por principios universales.

Es cierto, pues, que el niño no es demócrata. Pero es cierto también que su desarrollo natural conduce hacia la formación en él de una conciencia democrática. 
Ocurre, sin embargo, que en la sociedad contemporánea tal "desarrollo natural" suele verse con frecuencia truncado por las exigencias de la sociedad consumista. El juego vuelve a ser aquí ejemplo privilegiado. Basta comparar la inmensa diferencia que para la formación de los niños tienen los juegos en equipo (que se realizan bajo reglas claramente establecidas y en los cuales los niños se ven obligados a negociar las reglas y a interactuar cooperativamente con otros o incluso a someterse al juego de una sana competencia) y los juegos electrónicos, cada vez más frecuentes que, aparte de la carga de violencia e ideología de que son portadores y de la amplia manipulación de la conciencia que a través de ellos se ejerce, tienden a aislar a los niños unos de otros, a sobreestimular sus sentidos y los lleva a no actuar casi nunca en actividades cooperativas, sino, más bien, en una lucha ciega por alcanzar el triunfo a toda costa. Si la auténtica formación democrática precisa de un adecuado punto de partida, creo yo que el juego de los niños, que es precisamente el factor clave de toda su formación, debe ser reorientado en orden a recuperar lo que éste puede tener de catalizador social y de ejercicio primero y privilegiado de convivencia y tolerancia. El juego infantil que se funda en el valor del trabajo en equipo, de la competencia en igualdad de condiciones, del esfuerzo cooperativo es el mejor semillero de una auténtica educación democrática.

Y con esto vamos llegando al punto central: ¿en qué puede consistir esa auténtica formación democrática de que venimos hablando? Antes de enfrentar de un modo directo esta pregunta fundamental, permítanme una vez más que me remita a una anécdota aleccionadora. Pertenece a Alexander Neill, fundador y director de la famosa escuela libertaria de Summerhill en Inglaterra 1977.. El gobierno supremo de dicha escuela estaba conformado por los propios niños. En una ocasión en que ningún niño se postuló como miembro de dicho órgano de gobierno, Neill decidió proclamarse dictador. Esa misma tarde, Viviana, una niña de seis años, llegó a su oficina a comunicarle que había roto un vidrio. Como Neill no le puso cuidado, volvió al poco tiempo para decirle que ya había roto dos vidrios. Cuando éste quiso escuchar una explicación para el asunto, Viviana sólo le dijo "No me gustan los dictadores". Al preguntarle Neill lo que pensaba hacer, la niña respondió sin titubeos: "Romperé más vidrios". Poco tiempo después regresó para recordarle que ya llevaba diecisiete. Neill le comunicó que le correspondía pagarlos. La niña aceptó que debía ser así, pero que ello sólo sería posible cuando hubiera sido depuesto el dictador.

Esta sencilla anécdota no sólo puede tomarse como una muestra de lo aguda que puede llegar a ser la conciencia política de un niño que ha crecido en un ambiente de libertad, sino también lo sensibles que aún los niños pequeños resultan ser ante una autoridad ejercida de un modo ilegítimo. En este punto quisiera detenerme un instante: nada hay tan decisivo para la formación de criterios democráticos en un niño como el gozar de un sano sentido de la autoridad. Es cierto que un niño debe aprender a obedecer, pues, como decía una antigua sentencia atribuida a los Siete Sabios griegos, "sólo debe mandar quien previamente ha aprendido a obedecer". Pero es cierto también que la obediencia que educa es aquella que se prodiga a una autoridad ejercida con legitimidad y justicia. Quien se ha criado en un ambiente en donde hay reglas claras de juego y una autoridad que las administra 
sabiamente y que, en caso de violación de éstas, procede inmediatamente a la reparación de los daños causados o garantiza la protección de los más desvalidos, es alguien que, al crecer con un sano sentido de la autoridad, no sólo no se desgastará con los años en absurdos actos de rebeldía, sino que llegará a ejercer el poder cuando le toque sin arrogancias ni revanchismos. Una adecuada formación democrática implica, pues, la combinación de un ambiente de reflexión y diálogo entre iguales al mismo tiempo que un ejercicio de convivencia mediado por una autoridad legítima que, al tiempo que se ejerce sin complejos de culpa, está dispuesta ella también a escuchar razones y a examinar sus puntos de vista.

No nos debe conducir lo anterior, sin embargo, al equívoco según el cual la formación democrática es una mera cuestión de actitudes. Es también una cuestión de información y, sobre todo, de reflexión. Es decir, implica necesariamente un trato directo con y una instrucción específica sobre las instituciones e ideales que orientan la sociedad en la que vivimos y la toma de una postura razonada ante tales instituciones e ideales. El niño y el joven, en cuanto miembros activos de una sociedad democrática (y no sólo en su condición de futuros ciudadanos) deben conocer -más aún, están obligados a conocer- los principios que rigen el Estado y la sociedad de la que forman parte, así como sus deberes y derechos en cuanto ciudadanos actuales o potenciales. Deben por ello, además de conocer la Constitución que los rige, estar al tanto de los principales sucesos que acaecen en su entorno, discutir sobre algunos de los más graves fenómenos que afectan la vida de su país (narcotráfico, terrorismo, corrupción, violación de derechos fundamentales, etc.) y examinar cuidadosamente los conceptos claves que sirven de base a la vida democrática: tolerancia, justicia, libertad personal, aceptación de la diversidad étnica y cultural, etc. Ello, además, debe ir ligado a una práctica democrática específica: la que pueden desarrollar a través de las muchas actividades en que participan y ayudan a definir los derroteros de su propia educación, y muy especialmente a partir de su posibilidad de participación en el gobierno escolar.

Este deber-ser, aunque legítimo, tropieza, sin embargo, de entrada, con algunas dificultades fundamentales. Por una parte, no podemos desconocer que el propio ideal democrático pasa en muchas épocas por una crisis de legitimidad, sobre todo en países en que resulta habitual culpar al régimen de todas las injusticias y desigualdades y donde fácilmente nos dejamos conducir, desesperados por la falta de alternativas, hacia la tentación totalitaria. Por la otra, no podemos tampoco negar que son también niños y jóvenes los que en muchos casos representan algunos de los retos más terribles para la convivencia pacífica y tolerante; son en su gran mayoría menores de edad quienes conforman las bandas de sicarios o de "cabezas rapadas" que cometen los más terribles actos de violencia; y, puesto que contra ellos no se puede muchas veces ejercer legítimamente la fuerza y ni siquiera son fácilmente judicializables sus actos, es preciso repensar seriamente cómo cultivar en ellos un sentido de la existencia menos escéptico y más abierto a la perspectiva de otros.

La rebeldía de estos grupos no es, ciertamente, constructiva. Revela, sin embargo, un punto esencial del problema: la democracia no es algo que convoque a la 
juventud rebelde de hoy; es percibida por ellos como un lastre histórico que convendría suprimir. Y ello, creo yo, en gran parte se debe a que lo que ellos han sentido como democracia no es más que su aspecto meramente formal. Veámoslo en algunos ejemplos simples. Si uno de los criterios fuertes que hablan de la existencia de una democracia es la existencia de un Parlamento, ¿qué tan deseable puede ser ello cuando el Parlamento es en la gran mayoría de los países el foco por excelencia de la corrupción? Si una de las grandes promesas de la democracia es la de ofrecer mecanismos de participación ciudadana, ¿qué sentido tiene participar de una sociedad que ellos perciben como indeseable? Si se les insiste en que la democracia es el medio de garantizar una sociedad pacífica, ¿̇cómo se puede explicar el grado de violencia en que vivimos?

Queremos educar a los niños y jóvenes para la convivencia en una sociedad democrática. Ello nos parece legítimo. Conviene, sin embargo, que nos preguntemos: ¿para qué tipo de democracia los estamos educando? Si lo que ellos perciben como democracia no es más que una cuestión formal, resultará difícil que se sientan animados a compartir los ideales de esa sociedad democrática de la que con frecuencia les hablamos. Si, como ocurre con frecuencia, el gobierno escolar (que en la mayoría de los casos existe "por decreto" más que porque haya sido experimentado por los propios niños y jóvenes como una necesidad real) se limita a una representación formal de los alumnos en un consejo escolar, o cuando mucho a la realización de actividades y tareas rutinarias, es claro que el fin para el cual fue ideado -el de fomentar la participación entre los estudiantes- no sólo no se alcanza, sino que incluso se pervierte. Es decir, en vez de ayudar a que se forme en el alumno un sentido y una conciencia democrática, servirá para que el alumno perciba y aprenda lo que efectivamente muchas veces percibe y aprende: que la democracia es una cuestión de forma, y que la participación en ella no consiste más que en el cumplimiento de un requisito sin tener nunca consecuencias reales.

Ampliemos lo anterior a una escala mayor y veremos un comportamiento semejante. Si se le preguntara a los ciudadanos de uno de nuestros países, mediante una de esas encuestas de opinión tan en boga en nuestros días, si creen que su país es una democracia, muy seguramente la gran mayoría diría que sí. Y, si les preguntáramos los argumentos en que se basan para su afirmación, es muy probable que nos recordaran que tenemos una Constitución que consagra una serie de derechos, que tenemos un Parlamento, una división de los poderes públicos, o unos mecanismos de participación ciudadana y de defensa de los derechos individuales. Igualmente, si les preguntáramos a los alumnos de nuestros colegios si la institución educativa a la que pertenecen es democrática tenderían a decirnos que sí: los alumnos pueden opinar, existe un gobierno escolar, hay un manual de convivencia, los alumnos tienen una participación en el consejo superior del colegio, etc. Es claro que no puede ser otra la respuesta. Nuestro país y nuestros colegios cumplen con los requisitos para ser llamados democracias. Subsiste, sin embargo, la pregunta fundamental: clo son efectivamente? Si la democracia es una cuestión de formas y requisitos, no hay ningún problema. Pero si la democracia es más que esto, la respuesta no parece tan sencilla. 
Es ahora cuando los metacriterios que señalamos previamente (bien común, justicia, libertad individual) recobran todo su sentido. ¿Es nuestra institución un lugar en donde se trabaja efectivamente en busca del bien común o un espacio para el lucro de alguien o el desarrollo de intereses particulares? ¿Son justas las normas, las decisiones o los procedimientos que se practican en ella? ¿Está comprometida seriamente en el respeto del derecho de los individuos al libre desarrollo de su personalidad? Sólo una institución que sea efectivamente democrática estará en condiciones de formar para la democracia.

Con frecuencia, sin embargo, ponemos el énfasis de un modo excesivo en la educación para la democracia y rellenamos los programas de educación democrática de descripciones de nuestras instituciones políticas, de reflexiones emotivistas sobre nuestros símbolos patrios o de meras normas y principios constitucionales, descuidando lo que es aún más esencial: la educación en un ambiente democrático. La causa de ello es la misma que venimos señalando: nos conformamos con formas democráticas, en vez de arriesgarnos a vivir los compromisos que trae implícita una forma de vida democrática. Es decir, aceptamos la democracia como una "verdad de hecho" (es decir como algo ya dado e indiscutible que simplemente es así y no puede ser de otro modo) y no como una "verdad de razón", esto es, como algo que tiene sentido porque es razonable; más aún, porque es precisamente aquella forma de vida donde prima por sobre todas las otras cosas el criterio de la razonabilidad. Creemos en la democracia como una forma de gobierno, pero no nos atrevemos a aceptarla como una forma de vida. Vivir democráticamente, sin embargo, es algo que sólo se aprende en una comunidad en donde la exploración y revisión permanente de los criterios y metacriterios democráticos se convierte en práctica cotidiana. Llamamos a tal forma de vida democrática la comunidad de indagación.

\section{La comunidad de indagación como ámbito de formación democrática}

El conocimiento humano suele moverse entre dos extremos viciosos: la mera opinión y la posesión de verdades absolutas. Ambos extremos, cada uno a su manera, hacen imposible la convivencia democrática.

La mera opinión, es decir, la incapacidad para elevarse hacia puntos de vista universales en la consideración de las cosas, la tendencia a ver en ellas sólo su lado aparente y a quedarnos atados por nuestras propias representaciones, ha sido objeto de la crítica filosófica desde la antigüedad griega, especialmente por parte de Platón. La desgracia de una sociedad sometida a la tiranía de la opinión ha sido bellamente representada por éste en su famosa alegoría de la caverna, en donde se nos muestra a un conjunto de ciudadanos atados de pies y manos e incapaces de mover su cabeza en otra dirección distinta a la del fondo de una cueva en donde les son proyectadas imágenes engañosas que ellos toman por la realidad misma.

Algunos dirían que esa tal vez sea la desgracia de los hombres que no han encontrado la verdad. Sin embargo, olvidan éstos que la verdad puede ser tan tiránica como la opinión. Nada más ajeno al auténtico espíritu democrático que aquellos que se sienten dueños de la verdad, es decir, que piensan que han 
alcanzado "la visión correcta" del mundo y que, inspirados en esa visión, se creen investidos de la misión (misión que, por cierto, nadie les ha encomendado) de librar a los otros de la ignorancia o de salvarlos del que ellos han definido como el peor de los males: el paganismo, el comunismo, el ateísmo, etc. Si esa verdad se proclama, además, sacrosanta, y si quien la declara se proclama a su vez infalible, las consecuencias no pueden ser peores: una verdad absoluta reclama una obediencia absoluta.

Una auténtica democracia no puede florecer, entonces, ni en el mundo de la mera opinión ni en el reino de la verdad absoluta. En el primero porque allí no hay exigencia alguna de ser razonable, sino que cualquier opinión vale por sí misma, es decir, se autorrespalda en el mero recurso al sentimiento, la convicción o la experiencia de un sujeto aislado e incapaz de confrontación. En el segundo porque allí no hay nada que discutir; allí no se puede disentir y, mucho menos, desobedecer; allí se ordena y se ejecutan las órdenes; allí tampoco se puede ser razonable, pues simplemente ello resulta un estorbo.

La democracia, como bien lo señaló en su momento John Dewey(6), requiere de una nueva justificación epistemológica. Ello implica, por una parte, el reconocimiento de las dificultades inherentes a la vida democrática y una toma de conciencia en torno a la fragilidad de nuestro conocimiento del mundo; y, por la otra, un compromiso con la propia democracia como forma de vida personal. Ello, a su vez, sólo es posible por una nueva condición epistemológica que la hace posible: la indagación. El hombre auténticamente democrático es aquel que, a la vez que no se conforma con las opiniones establecidas ni se detiene en supuestas verdades últimas, somete todo a permanente examen, es decir, indaga por los supuestos y las implicaciones de cuanto hace, dice, siente o piensa. Dicha indagación, además, no es una búsqueda cualquiera. Consiste en el propósito explícito de examinar toda institución, al igual que toda práctica social o forma de creencia, a la luz de criterios relevantes que permitan determinar su consistencia y adecuación a los metacriterios democráticos que previamente hemos señalado. Indagar es, pues, la tarea permanente de aquel que cree en la democracia como forma de vida; y que cree, sobre todo, como lo señalara Sócrates en su discurso ante el tribunal ateniense, que "una vida sin examen no merece ser vivida".

Dicha indagación, sin embargo, no se manifiesta exclusivamente en el afán deliberado de someter a crítica nuestras prácticas sociales, sino especialmente en la permanente voluntad de autoexamen y de cuidado de sí. "Conócete a ti mismo" y "Cuida de ti mismo" rezan las dos máximas fundamentales de la ética griega. Ellas son, por cierto, los imperativos fundamentales del hombre democrático, es decir de quien se compromete personalmente con la democracia como forma de vida. $\mathrm{El}$ autoexamen y el cuidado de sí no son, sin embargo, prácticas solipsistas. Son ante todo el resultado del compromiso con una comunidad. La propia constitución del yo, como lo han destacado autores como George Herbert Mead y Lev Vygotski, es un proceso de internalización de la propia imagen de nosotros mismos que nos formamos en permanente interacción con los demás. Vivir democráticamente es precisamente aceptar la mediación de la comunidad en la constitución de lo que 
somos, pensamos o deseamos. Sin democracia no hay comunidad. Sin comunidad no hay democracia.

Ahora bien. ¿Qué tipo de comunidad es la que se requiere para la formación del carácter democrático? No ciertamente una comunidad donde meramente se comparten opiniones sin que se exija a los individuos que las sometan a examen. Tampoco una comunidad que se une para defender una verdad establecida, para afirmar o defender un dogma o una doctrina. La comunidad democrática es y ha de ser una comunidad de indagación, es decir, una comunidad en donde se cultivan cierto tipo de hábitos y habilidades: una comunidad dispuesta al diálogo y al cuestionamiento; una comunidad que no busca puntos de vista uniformes ni verdades últimas, sino despliegue de diversas perspectivas; una comunidad en la cual no se busca derrotar al otro en la argumentación, sino enriquecernos con su punto de vista; una comunidad de investigación reflexiva en donde se examinan los supuestos y consecuencias de nuestros actos y palabras; una comunidad donde se cultiva el buen juicio, es decir, el juicio basado en criterios que es capaz de autocorregirse y es sensible al contexto.

En la comunidad de indagación los individuos se liberan de la necesidad de tener siempre la razón, aprenden de sus propios errores y, sobre todo, se preocupan del crecimiento vital de cada uno de sus miembros. Se combina allí una atención permanente a los tópicos que son objeto de examen y un cuidado riguroso con los procedimientos lógicos que garantizan la coherencia de nuestro examen. Priman allí los criterios democráticos sobre los totalitarios: el diálogo sobre la imposición, la indagación sobre la verdad, la tolerancia sobre el deseo de crear patrones uniformes, el desarrollo personal sobre las exigencias de someterse a los dictados de la colectividad.

Dicha comunidad de indagación puede empezar ya a vivirse desde los primeros años de la infancia por parte de niños que aprenden a escucharse mutuamente, que se acostumbran a dar razones en orden a justificar sus actos, que se entrenan en el mejoramiento de su capacidad de razonar, que se empeñan en hacer buenas distinciones y relaciones y en realizar inferencias válidas, en detectar supuestos, en buscar ejemplos y contraejemplos, en plantear buenas preguntas, en reconocer falacias lógicas, en inferir consecuencias, en detectar supuestos, en definir los términos que utilizan, en elaborar analogías, en buscar puntos de vista alternativos, etc., es decir, que hacen del buen pensamiento una tarea vital en la que se comprometen de un modo personal. Y ello precisamente porque la democracia es precisamente una forma de vida fundada en el ejercicio de la razón.

Y llegamos con esto al punto que consideramos crucial: si la democracia es una forma de vida basada en el ejercicio de la razón, la formación democrática es, en primer lugar y fundamentalmente, la preparación para el buen uso de nuestra razón. Puesto que ella ha sido desde siempre el tema por excelencia de la filosofía, la formación democrática de niños y jóvenes no puede hacerse al margen del pensar filosófico. No podemos los maestros hacer un mayor aporte a la vida democrática que el de promover una educación que efectivamente prepare a los niños y jóvenes para un ejercicio pleno de su razón. En ello consiste la propuesta 
de "Filosofía para Niños": en la constitución de una educación centrada en el ejercicio del pensar, o como lo llamara en su momento Estanislao Zuleta (1995) "una educación filosófica". Como bien dijera este último:

En la medida en que queramos que la educación signifique algo más que el entrenamiento de un experto para un mercado que lo demanda y que busquemos la formación de un ciudadano, en esa misma medida deberíamos acentuar la educación filosófica. Hay muchas cosas en la educación que no podemos evitar..., pero sí hay una cosa que podemos mejorar: pensar nosotros mismos lo que llamamos nuestras materias, impregnarlas de inquietudes y transmitirles entusiasmo, que es muchas veces lo que menos se transmite (...). La promoción de una educación filosófica es la forma por excelencia de búsqueda de ampliación de la democracia dentro del sistema educativo.

\section{Bibliografia}

LIPMAN, Matthew. Mark. New Jersey: IAPC, 1980.

. Pensamento complejo y educación. Madrid: Ediciones de la Torre, 1997.

MATTHEWS, Gareth. El niño y la filosofía. México: FCE, 1986.

NEILL, Alexander. Summerhill. Un punto de vista radical sobre la educación de los niños. México: FCE, 1977.

RAWLS, John. Teoría de la justicia. México: FCE, 1998.

ZULETA, Estanislao. Educación y democracia. Un campo de combate. Bogotá: Corporación Tercer Milenio - Fundación Estanislao Zuleta, 1995.

\section{Notas}

(1) Profesor Asociado Facultad de Filosofía Pontificia Universidad Javeriana. Correio eletrônico: diegopi@javeriana.edu.co

(2) Cfr. LIPMAN, Matthew: Mark, Montclair (New Jersey), IAPC, 1980. En la actualidad estoy terminando una traducción y adaptación de este texto para Colombia.

(3) Esta distinción es elaborada en muchos textos de Lipman, especialmente en Pensamiento complejo y educación, Madrid, Ediciones de la Torre, 1997, capítulos 6, 7 y 8.

(4) Véase al respecto, de Guillermo de Humboldt, su bellísimo texto "Ideas para un ensayo de determinación de los límites que circunscriben la acción del Estado", en sus Escritos políticos, México, F.C.E., 1983, pp. 87-164. De John Stuart Mill se puede leer 
especialmente su famoso ensayo Sobre la libertad, del que hay múltiples ediciones en lengua española.

(5) Puede verse a este respecto su famoso texto de 1784 "¿Qué es la ilustración?", del que existen también múltiples versiones en lengua española.

(6) Cfr. a este respecto el bello ensayo que sobre este asunto escribe Hilary Putnam en su texto Cómo renovar la filosofía, Barcelona, Cátedra, 1994. 